\title{
A atividade física voluntária e suas relações sobre a neurogênese hipocampal em roedores adultos - Uma revisão de literatura
}

\author{
Voluntary physical activity and its relationship to hippocampal \\ neurogenesis in adult rodents - A literature review
}

Anelise Bavaresco

\begin{abstract}
Esta revisão objetivou sistematizar as informações sobre a atividade física voluntária em roda de correr e sua relação com a neurogênese hipocampal na fase adulta. A pesquisa foi realizada na base de dados eletrônica US National Library of Medicine (PubMED). Foram incluídos artigos originais que abordassem o uso de roedores e a corrida voluntária como modelo de exercício; que relatassem a ocorrência de neurogênese hipocampal na fase adulta; publicados nos últimos cinco anos; disponíveis na íntegra; em inglês ou português. Foram excluídos: artigos de revisão; que abordassem a neurogênese humana; que se utilizassem de outros modelos de exercício físico; que não obedecessem aos critérios de inclusão. A busca eletrônica identificou 28 artigos relevantes, dos quais três não analisaram a ocorrência de neurogênese hipocampal e três não avaliaram a ocorrência da neurogênese na fase adulta, sendo então excluídos e restando 22 publicações. Os estudos avaliaram um total de 16 espécies diferentes de roedores, com predominância da linhagem de camundongos C57BL/6. O tempo de exposição à roda de corrida variou entre três dias e seis meses. Em conclusão, fatores como diferenças genéticas, neurotrofinas e a relação com o desenvolvimento de um comportamento ansioso interferem na expressão da neurogênese hipocampal na fase adulta após a atividade física voluntária. Essas evidências servem para nortear novos estudos a fim de melhor elucidar os mecanismos pelos quais esses fenômenos ocorrem, contudo, é indubitável o benefício que a prática regular de exercício físico, pode trazer aos indivíduos com neuropatologias.
\end{abstract}

\section{Keywords}

Atividade física; Exercício físico; Neurogênese; Hipocampo

\section{Resumo}

This review aimed to systematize information about the voluntary physical activity in wheel running and its relationship to adult bippocampal neurogenesis. The search was conducted in the electronic database US National Library of Medicine (PubMED). It were included original articles that addressed the use of rodents and the voluntary running as an exercise model; who reported the occurrence of hippocampal adult neurogenesis; published in the last five years; full text available; in English or Portuguese. The exclusion criteria were: review articles; that addressed the human neurogenesis; that used other exercise models; that not met the inclusion criteria. The electronic search identified 28 relevant articles, of which three did not analyze the occurrence of hippocampal neurogenesis and three did not evaluate the occurrence of neurogenesis in adults, being excluded and therefore remaining 22 publications. The studies evaluated a total of 16 different species of rodents, especially the C57BL/6 mouse strain. The running wheel exposure time ranged between three days and six months. In conclusion, factors such as genetic differences, neurotrophins and their relationship with the development of an anxious behavior interfere in the expression of hippocampal neurogenesis in adulthood after the voluntary physical activity. This evidence serve to guide further studies to further elucidate the mechanisms by which these phenomena occur, however, is undoubtedly the benefit that regular physical exercise can bring to individuals with neuropathology.

\section{Palavras-chave}

Physical Activity; Physical Exercise; Neurogenesis; Hippocampus

\section{Introdução}

O cérebro produz novos neurônios todos os dias,

1 Universidade Federal de Santa Catarina, Centro de Desportos, Florianópolis, Santa Catarina, Brasil. através de um fenômeno denominado neurogênese, descrito pela primeira vez por Altman e Altman ${ }^{1}$. A neurogênese tem início na fase pré-natal, continua no cérebro adulto e ainda ocorre durante o envelhecimento, principalmente em dois nichos neurogênicos 
especializados nos mamíferos: a zona subventricular (SVZ) do ventrículo lateral e a zona subgranular (SGZ) do giro denteado (GD) do hipocampo ${ }^{2,3}$, uma região com essencial contribuição nos processos de aprendizagem e memória ${ }^{3}$.

Durante o desenvolvimento cerebral, células neuroepiteliais telencefálicas, incluindo células-tronco neurais, dividem-se simetricamente no início da sua formação para aumentar o seu próprio número ${ }^{4}$. Estas células então promovem a neurogênese, principalmente através da divisão assimétrica, cada uma originando duas células filhas distintas: uma célula-tronco neural com o mesmo potencial da célula-mãe, e um neurônio ${ }^{4}$.

A neurogênese é um processo que consiste em quatro estágios: proliferação celular, que é regulada por uma variedade de estímulos, como exercício físico e moléculas sinalizadoras, que são expressas ou secretadas por componentes celulares dos nichos neurogênicos ${ }^{5,6}$; migração celular, que acontece através do fluxo migratório rostral até o bulbo olfatório, onde se estabelecem em camadas neuronais distintas, através da migração radial'; diferenciação neuronal, que é a evolução da glia para células-tronco neurais e; integração, controlada por neurotransmissores e pela atividade neural ${ }^{8}$. Após a diferenciação terminal, os novos neurônios pós-mitóticos sobrevivem e tornam-se células granulares ${ }^{9}$ e, somente após estes estágios, os neurônios são incorporados ao cérebro maduro.

Os neurônios nascidos na SVZ migram por grandes distâncias através da banda migratória rostral (do inglês rostral migratory stream - RMS) ${ }^{6}$ e tornam-se então neurônios granulares e periglomerulares. Neurônios nascidos na SGZ adulta migram pela camada celular granular do GD e nele se tornam células granulares ${ }^{10}$.

As células-tronco neurais representam um tipo especial de células somáticas com capacidade para auto-renovação em longo prazo e para a geração de diferentes linhagens neurais. Elas residem na SGZ e são a fonte desses novos neurônios, pois originam as células progenitoras neurais, que finalmente se diferenciam em novos neurônios maduros ${ }^{11,12}$. As células tronco neurais incluem células gliais radiais (tipo 1) e células progenitoras (tipo $2 \mathrm{a})^{13}$. Estas células possuem a capacidade de auto-regeneração e de gerar os três mais importantes tipos celulares do sistema nervoso central: neurônios, astrócitos e oligodendrócitos ${ }^{3,4,14}$.

Diversas condições fisiológicas e patológicas podem estimular a neurogênese na fase adulta, como o ambiente enriquecido, os fatores de crescimento, os hormônios, como a corticosterona e o exercício físico, o qual pode influenciar a proliferação, a sobrevivência e a diferenciação celular de neurônios recém-nascidos a neurônios maduros ${ }^{15}$. O exercício físico tem se mostrado um componente essencial para os processos cognitivos através do aumento do número de novas células hipocampais ${ }^{16}$, facilitação da recuperação de danos cerebrais ${ }^{17}$ e melhora da função cognitiva e do desempenho em testes de aprendizagem e memória ${ }^{9,18-21}$.

Diversos estudos demonstram que atividade física é um indutor robusto do aumento da neurogênese no giro denteado em animais jovens, adultos e ido$\operatorname{sos}^{9,10,12,16,21,30,49}$. A mesma exerce um efeito pró-proliferativo agindo primeiramente sobre os progenitores neurais do hipocampo ${ }^{(49)}$. Existe ainda um efeito não-independente presumível nos estágios subseqüentes do desenvolvimento neuronal, envolvendo a promoção de sobrevivência. Mesmo quando o efeito da proliferação retorna a níveis basais, a população de células continua a aumentar ${ }^{49}$.

Desta forma, a presente revisão objetivou sistematizar as informações dos estudos publicados de 2010 a 2015 sobre a atividade física voluntária em roda de correr e sua relação com a neurogênese hipocampal na fase adulta. 


\section{Métodos}

O presente estudo consiste em uma revisão sistemática de literatura sobre exercício físico voluntário e neurogênese na região hipocampal em animais adultos. A pesquisa foi realizada na base de dados eletrônica US National Library of Medicine (PubMED), através da consulta pelos seguintes descritores: exercício físico, atividade física e neurogênese.

A busca dos estudos foi realizada nos idiomas inglês e português, utilizando os seguintes descritores do Medical Subject Headings (MeSH): exercício físico (physical exercise), atividade física (physical activity) e neurogênese (neurogenesis). O operador booleano $A N D$ foi utilizado para fazer a busca simultânea de descritores, visando garantir a inclusão de todos os artigos potencialmente relevantes e a precisão da busca destes estudos.

Critérios de inclusão: Artigos originais que abordassem o uso de modelos animais e a roda de corrida voluntária como modelo de exercício; que relatassem a ocorrência de neurogênese na região hipocampal na idade adulta; publicados nos últimos cinco anos; disponíveis em formato de texto na íntegra; nos idiomas inglês ou português.

Critérios de exclusão: Artigos de revisão; artigos que abordassem a neurogênese humana; artigos que se utilizassem de outros modelos de exercício físico, como esteira e natação; aqueles que não obedeceram aos critérios de inclusão supracitados.

A seleção e a avaliação dos artigos encontrados foram realizadas em três etapas. $\mathrm{Na}$ primeira etapa foi realizada a leitura dos títulos de estudos potencialmente relevantes para a revisão da literatura. Foram excluídos aqueles que não se adequaram a qualquer um dos critérios de inclusão deste estudo ou que fossem repetidos. $\mathrm{Na}$ segunda etapa foi realizada a leitura dos resumos dos artigos e selecionados aqueles que atendiam aos critérios de inclusão pré-determinados. Na terceira etapa todos os estudos considerados relevantes foram obtidos na íntegra, lidos e analisados, resultando nos artigos que compuseram esta revisão sistemática.

As seguintes informações foram extraídas dos estudos incluídos nesta revisão: local e ano de publicação; espécie utilizada na pesquisa e grupos experimentais; objetivo principal do estudo; tempo de exposição à roda de correr e os principais resultados da pesquisa (Tabela 1$)$.

\section{Resultados}

A busca eletrônica permitiu identificar 166 artigos potencialmente relevantes para esta revisão. Destes, 96 foram excluídos por não utilizarem a roda de corrida como modelo de exercício físico. Dos 70 artigos que utilizaram a roda de corrida, 28 foram publicados nos últimos cinco anos. Após a leitura dos artigos verificou-se que destes, três não analisaram a ocorrência de neurogênese hipocampal, e três não avaliaram a ocorrência da neurogênese na fase adulta, sendo então excluídos (Figura 1). Após as etapas de seleção restaram 22 publicações que estão sistematizadas na tabela 1 . Adicionalmente, 50 estudos condizentes com o objetivo desta revisão foram incluídos na discussão dos resultados a fim de enriquecer a mesma, porém, por não estarem de acordo com os critérios de inclusão não estão descritos na tabela.

Das publicações restantes foram encontrados estudos de oito países, sendo que Estados Unidos ${ }^{22-32}$ e Alemanha ${ }^{33-37}$ concentraram o maior número de publicações. Ainda, Japão ${ }^{38}$, Canadá ${ }^{39}$, Espanha ${ }^{40}$, China ${ }^{41}$, Suíça ${ }^{42}$ e Holanda ${ }^{43}$ figuraram com um estudo cada. Os estudos avaliaram um total de 16 espécies diferentes de roedores, com predominância dos machos sobre as fêmeas e da linhagem de camun- 
TABELA 1 - Características dos artigos selecionados por esta revisão, sobre a ocorrência da neurogênese hipocampal na fase adulta em diferentes linhagens de animais, através da corrida voluntária na roda.

\begin{tabular}{|c|c|c|c|c|}
\hline $\begin{array}{l}\text { Referência e local do } \\
\text { estudo }\end{array}$ & Animais e grupos & Objetivo & $\begin{array}{l}\text { Tempo de } \\
\text { exposição à roda } \\
\text { de corrida }\end{array}$ & Principais Resultados \\
\hline $\begin{array}{l}\text { Fuss et al., }(2010)^{34} \\
\text { Alemanha }\end{array}$ & $\begin{array}{l}\text { Camundongos C57BL/6 } \\
\text { machos } \\
\text { Sedentários Sham } \\
\text { Corredores Sham } \\
\text { Sedentários Irradiados } \\
\text { Corredores Irradiados }\end{array}$ & $\begin{array}{l}\text { Investigar se a correlação entre } \\
\text { neurogênese e ansiedade é } \\
\text { apenas um epifenômeno ou se } \\
\text { constitui numa relação causal. }\end{array}$ & $\begin{array}{l}33 \text { dias } \\
4 \text { semanas }\end{array}$ & $\begin{array}{l}\text { O aumento excessivo da } \\
\text { neurogênese pode ter efeitos } \\
\text { negativos para a saúde mental. }\end{array}$ \\
\hline $\begin{array}{l}\text { Wong-Goodrich et al., } \\
(2010)^{29} \\
\text { EstadosUnidos }\end{array}$ & $\begin{array}{l}\text { Camundongos C57BL/6 fêmeas } \\
\text { Sedentários Sham } \\
\text { Corredores Sham } \\
\text { Sedentários Irradiados } \\
\text { Corredores Irradiados }\end{array}$ & $\begin{array}{l}\text { Investigar os efeitos da corrida } \\
\text { voluntária na memória, na } \\
\text { aprendizagem espacial e na } \\
\text { neurogênese hipocampal em } \\
\text { um modelo adulto de irradiação } \\
\text { cerebral }\end{array}$ & 6 semanas & $\begin{array}{l}\text { A corrida pode reverter o } \\
\text { declínio da memória e auxiliar } \\
\text { na recuperação da plasticidade } \\
\text { hipocampal adulta, destacando, } \\
\text { assim, o exercício como uma } \\
\text { potencial intervenção terapêutica. }\end{array}$ \\
\hline $\begin{array}{l}\text { Kohman et al, (2011)31 } \\
\text { Estados Unidos }\end{array}$ & $\begin{array}{l}\text { Camundongos BALB/c machos } \\
\text { Sedentários Adultos } \\
\text { Corredores Adultos } \\
\text { Sedentários velhos } \\
\text { Corredores velhos }\end{array}$ & $\begin{array}{l}\text { Avaliar as mudanças na expressão } \\
\text { dos genes hipocampais } \\
\text { relacionadas com a idade e se o } \\
\text { exercício aeróbio diferentemente } \\
\text { modula a expressão dos genes em } \\
\text { camundongos adultos e velhos. }\end{array}$ & 60 dias & $\begin{array}{l}\text { Os efeitos benéficos do exercício } \\
\text { parecem resultar em mudanças } \\
\text { em múltiplos padrões que podem } \\
\text { ser restaurativos em sujeitos } \\
\text { envelhecidos, mas também agem } \\
\text { como medida preventiva em } \\
\text { sujeitos jovens. }\end{array}$ \\
\hline $\begin{array}{l}\text { Mustroph et al., (2011) } \\
\text { Estados Unidos }\end{array}$ & $\begin{array}{l}\text { Camundongos (57BL/6) } \\
\text { machos } \\
\text { Sedentários } \\
\text { Corredores }\end{array}$ & $\begin{array}{l}\text { Verificar se o tempo de exercício } \\
\text { relativo ao condicionamento } \\
\text { tem efeitos opostos em relação à } \\
\text { cocaína. }\end{array}$ & 30 dias & $\begin{array}{l}\text { A corrida dobrou o número de } \\
\text { novos neurônios em comparação } \\
\text { ao grupo sedentário. }\end{array}$ \\
\hline $\begin{array}{l}\text { Clark et al., (2011) } \\
\text { Estados Unidos }\end{array}$ & $\begin{array}{l}\text { Camundongos 129S1/SvlmJ, } \\
\text { AKR/J, B6129SF1/J, B6D2F1/J, } \\
\text { BALB/CByJ, BTBRT+ tf/J, } \\
\text { C57BL/10J, C57BL/6J, CAST/ } \\
\text { EiJ, DBA/2J, NOD/ShiLtJ e SM/J } \\
\text { machos e fêmeas; } \\
\text { Sedentários } \\
\text { Corredores }\end{array}$ & $\begin{array}{l}\text { Comparar a neurogênese } \\
\text { hipocampal adulta induzida } \\
\text { pelo exercício em } 12 \text { espécies } \\
\text { geneticamente diferentes. }\end{array}$ & 43 dias & $\begin{array}{l}\text { A neurogênese não diferiu em } \\
\text { animais sedentários e corredores; } \\
\text { A atividade física não foi } \\
\text { significativamente geneticamente } \\
\text { correlacionada com os níveis } \\
\text { de neurogênese em condições } \\
\text { sedentárias. }\end{array}$ \\
\hline $\begin{array}{l}\text { Clark et al., (2011) } \\
\text { Estados Unidos }\end{array}$ & $\begin{array}{l}\text { Camundongos C57BL/6J } \\
\text { fêmeas } \\
\text { Sedentários } \\
\text { Corredores }\end{array}$ & $\begin{array}{l}\text { Determinar se a ativação da } \\
\text { neurogênese está relacionada } \\
\text { com a distância percorrida em } \\
\text { gaiolas sem rodas de correr }\end{array}$ & 31 dias & $\begin{array}{l}\text { A indução da neurogênese é } \\
\text { específica para a roda de corrida e } \\
\text { não ocorre em níveis mais baixos } \\
\text { de atividade física como a exibida } \\
\text { no grupo sedentário. }\end{array}$ \\
\hline $\begin{array}{l}\text { Marlatt, et al., }(2012)^{43} \\
\text { Holanda }\end{array}$ & $\begin{array}{l}\text { Camundongos C57BL/6J } \\
\text { fêmeas } \\
\text { Sedentários } \\
\text { Corredores }\end{array}$ & $\begin{array}{l}\text { Determinar os efeitos da corrida } \\
\text { em longo prazo na neurogênese } \\
\text { hipocampal na fase adulta, nos } \\
\text { níveis de BDNF, na aprendizagem } \\
\text { espacial e no comportamento } \\
\text { motor. }\end{array}$ & 6 meses & $\begin{array}{l}\text { A neurogênese hipocampal e os } \\
\text { níveis de BDNF foram elevados; } \\
\text { Também houve melhoras na } \\
\text { retenção da memória espacial } \\
\text { e um modesto aumento no } \\
\text { desempenho no teste do rotarod. }\end{array}$ \\
\hline $\begin{array}{l}\text { Klaus et al., }(2012)^{27} \\
\text { Estados Unidos }\end{array}$ & $\begin{array}{l}\text { Camundongos C57BL/6 fêmeas } \\
\text { Camundongos domésticos } \\
\text { Europeus machos e fêmeas } \\
\text { Sedentários } \\
\text { Corredores }\end{array}$ & $\begin{array}{l}\text { Investigar a diferenças no } \\
\text { desempenho na corrida, na } \\
\text { proliferação e na morte celular } \\
\text { entre os grupos. }\end{array}$ & 2 semanas & $\begin{array}{l}\text { Os resultados implicam uma } \\
\text { diferença na regulação da } \\
\text { neurogênese em camundongos, } \\
\text { sendo maior em C } 57 \mathrm{BL} / 6 \text { do que } \\
\text { em camundongos domésticos. }\end{array}$ \\
\hline $\begin{array}{l}\text { Yau et al., }(2012)^{41} \\
\text { China }\end{array}$ & $\begin{array}{l}\text { Ratos Sprague-Dawley machos } \\
\text { Controle sedentários } \\
\text { Controle corredores } \\
\text { Corticosterona sedentários } \\
\text { Corticosterona corredores }\end{array}$ & $\begin{array}{l}\text { Investigar o efeito agudo e crônico } \\
\text { do tratamento com corticosterona, } \\
\text { com ou sem corrida na roda na } \\
\text { memória, no aprendizado e na } \\
\text { proliferação celular hipocampal e nos } \\
\text { níveis periféricos de BDNF e IGF-1 }\end{array}$ & $\begin{array}{l}5 \text { dias - agudo } \\
28 \text { dias - crônico }\end{array}$ & $\begin{array}{l}\text { O tratamento agudo com } \\
\text { corticosterona melhorou a } \\
\text { aprendizagem espacial e elevou } \\
\text { os níveis de BDNF no plasma e no } \\
\text { hipocampo, porém não afetou a } \\
\text { proliferação de células do hipocampo }\end{array}$ \\
\hline $\begin{array}{l}\text { Clark et al., }(2012)^{27} \\
\text { Estados Unidos }\end{array}$ & $\begin{array}{l}\text { Camundongos C } 57 \mathrm{BL} / 6 \mathrm{~J} \\
\text { fêmeas } \\
\text { Sedentários } \\
\text { Corredores }\end{array}$ & $\begin{array}{l}\text { Determinar se novos neurônios } \\
\text { gerados a partir da corrida são } \\
\text { ativados seletivamente pela corrida, } \\
\text { ou podem ser recrutados para a } \\
\text { atividade das células granulares } \\
\text { que ocorre durante a execução de } \\
\text { outras tarefas comportamentais } \\
\text { que envolvem o hipocampo. }\end{array}$ & 30 dias & $\begin{array}{l}\text { Camundongos do grupo dos } \\
\text { corredores apresentaram um } \\
\text { aumento de } 4 \text { vezes no número } \\
\text { de células Zif268 positivas em } \\
\text { relação ao grupo controle. }\end{array}$ \\
\hline
\end{tabular}


...continua

\begin{tabular}{|c|c|c|c|c|}
\hline $\begin{array}{l}\text { Referência e local do } \\
\text { estudo }\end{array}$ & Animais e grupos & Objetivo & $\begin{array}{l}\text { Tempo de } \\
\text { exposição à roda } \\
\text { de corrida }\end{array}$ & Principais Resultados \\
\hline $\begin{array}{l}\text { Onksen et al., }(2012)^{28} \\
\text { Estados Unidos }\end{array}$ & Camundongos C57BL/6 & $\begin{array}{l}\text { Investigar se a deleção da } \\
\text { proteína rad-3 do hipocampo } \\
\text { resulta em resistência aos efeitos } \\
\text { neurogênicos de exercício } \\
\text { voluntário e examinar as } \\
\text { implicações comportamentais } \\
\text { dessa resistência. }\end{array}$ & 4 semanas & $\begin{array}{l}\text { A corrida na roda resultou } \\
\text { num aumento da proliferação } \\
\text { celular e neurogênese e em um } \\
\text { aumento da ansiedade nos testes } \\
\text { comportamentais. No entanto, } \\
\text { ambos os efeitos neurogênicos e } \\
\text { ansiogênicos da roda de corrida } \\
\text { foram atenuados pela deleção } \\
\text { hipocampal da rad-3, sugerindo } \\
\text { que o aumento da neurogênese } \\
\text { é um importante mediador da } \\
\text { ansiedade induzida pelo exercício. }\end{array}$ \\
\hline $\begin{array}{l}\text { Kohman et al., }(2012)^{30} \\
\text { Estados Unidos }\end{array}$ & $\begin{array}{l}\text { Camundongos (57BL/6) } \\
\text { machos } \\
\text { Sedentários } \\
\text { Corredores }\end{array}$ & $\begin{array}{l}\text { Avaliar se a corrida voluntária } \\
\text { aumenta o desempenho } \\
\text { contextual e no traço } \\
\text { condicionado e se os efeitos } \\
\text { benéficos do exercício dependem } \\
\text { do tempo de intervalo entre treino } \\
\text { e teste. }\end{array}$ & 60 dias & $\begin{array}{l}\text { A corrida na roda aumenta o } \\
\text { desempenho cognitivo em } \\
\text { algumas tarefas, mas não em } \\
\text { outras e que o aumento da } \\
\text { neurogênese nem sempre está } \\
\text { associado com a melhora do } \\
\text { desempenho das tarefas do } \\
\text { hipocampo. }\end{array}$ \\
\hline $\begin{array}{l}\text { Garrett et al., }(2012)^{37} \\
\text { Alemanha }\end{array}$ & $\begin{array}{l}\text { Camundongos (57BL/6) } \\
\text { machos }\end{array}$ & $\begin{array}{l}\text { Avaliar os efeitos de } 14 \text { e } 28 \\
\text { dias de corrida voluntária na } \\
\text { proliferação, diferenciação, } \\
\text { sobrevivência e maturação dos } \\
\text { neurônios nascidos no GD. }\end{array}$ & $\begin{array}{l}2 \text { semanas } \\
4 \text { semanas }\end{array}$ & $\begin{array}{l}14 \text { dias de corrida provém } \\
\text { um aumento no número de } \\
\text { células Ki67 positivas no GD em } \\
\text { comparação aos controles. } \\
28 \text { dias de corrida provém } \\
\text { um aumento no número de } \\
\text { células BrdU positivas no GD em } \\
\text { comparação aos controles. }\end{array}$ \\
\hline $\begin{array}{l}\text { Maynard e Leasure } \\
(2013)^{23} \\
\text { Estados Unidos }\end{array}$ & $\begin{array}{l}\text { Ratos Long-Evans Fêmeas } \\
\text { Sedentários } \\
\text { Exercício }\end{array}$ & $\begin{array}{l}\text { Verificar se o exercício aumenta a } \\
\text { sobrevivência das células geradas } \\
\text { no GD após a exposição ao etanol, } \\
\text { normalizando assim, tanto o } \\
\text { volume do DG como o número de } \\
\text { neurônios granulares. }\end{array}$ & 4 semanas & $\begin{array}{l}\text { A exposição ao etanol causou } \\
\text { danos no hipocampo em ratos } \\
\text { fêmeas, e que esse dano foi } \\
\text { completamente revertido pelo } \\
\text { exercício. }\end{array}$ \\
\hline $\begin{array}{l}\text { Overall et al., }(2013)^{33} \\
\text { Alemanha }\end{array}$ & $\begin{array}{l}\text { Camundongos DBA/2JRj e } \\
\text { C57BL/6JRj fêmeas } \\
\text { Sedentários } \\
\text { Corredores }\end{array}$ & $\begin{array}{l}\text { Investigar as respostas à } \\
\text { proliferação relacionada à corrida } \\
\text { na roda numa comparação entre } \\
\text { as espécies DBA/2 e C } 57 \mathrm{BL} / 6 \text {. }\end{array}$ & $\begin{array}{l}4 \text { dias } \\
28 \text { dias } \\
2 \text { semanas } \\
3 \text { semanas } \\
6 \text { semanas }\end{array}$ & $\begin{array}{l}\text { O efeito da corrida voluntária sobre a } \\
\text { proliferação de precursores neuronais } \\
\text { é diferente em camundongos DBA/2 } \\
\text { em comparação com camundongos } \\
\text { C57BL/6 }\end{array}$ \\
\hline $\begin{array}{l}\text { Nishijima et al., }(2013)^{38} \\
\text { Japão }\end{array}$ & $\begin{array}{l}\text { Camundongos C57BL/6 } \\
\text { machos } \\
\text { Sedentários } \\
\text { Corredores }\end{array}$ & $\begin{array}{l}\text { Investigar a correlação associativa } \\
\text { entre a expressão de FosB/ } \triangle \text { FosB } \\
\text { e neurogênese como implicações } \\
\text { funcionais de indução de } \Delta \text { FosB } \\
\text { pelo exercício na regulação da } \\
\text { plasticidade do hipocampo. }\end{array}$ & 4 semanas & $\begin{array}{l}\text { O exercício físico em longo prazo } \\
\text { é um potente mecanismo indutor } \\
\text { de } \triangle \text { FosB em todo o hipocampo, } \\
\text { o que explicaria a melhora nas } \\
\text { funções dependentes das regiões } \\
\text { dorsal e ventral. }\end{array}$ \\
\hline $\begin{array}{l}\text { Liu et al., }(2013)^{26} \\
\text { Estados Unidos }\end{array}$ & $\begin{array}{l}\text { Camundongos } \mathrm{C} 3 \mathrm{H} / \mathrm{HeN} \\
\text { machos } \\
\text { Sedentários Melatonina } \\
\text { Sedentários Veículo } \\
\text { Corredores Melatonina } \\
\text { Corredores Veículo }\end{array}$ & $\begin{array}{l}\text { Avaliar o papel da melatonina } \\
\text { na modulação da neurogênese } \\
\text { induzida pela corrida voluntária. }\end{array}$ & 40 dias & $\begin{array}{l}\text { A melatonina potencializa } \\
\text { a neurogênese hipocampal } \\
\text { induzida pela corrida voluntária, } \\
\text { aumentando a sobrevivência } \\
\text { neuronal, sugerindo que a } \\
\text { combinação de exercício físico } \\
\text { e melatonina pode ser um } \\
\text { tratamento eficaz para as doenças } \\
\text { que afetam a neurogênese } \\
\text { hipocampal. }\end{array}$ \\
\hline $\begin{array}{l}\text { Fuss et al., }(2013)^{35} \\
\text { Alemanha }\end{array}$ & $\begin{array}{l}\text { Camundongos C57BL/6J } \\
\text { machos } \\
\text { Sedentários irradiados } \\
\text { Sedentários não irradiados } \\
\text { Corredores irradiados } \\
\text { Corredores não irradiados }\end{array}$ & $\begin{array}{l}\text { Investigar a ligação do hipocampo } \\
\text { e a função dos receptores 5-HT1A } \\
\text { em um modelo de ansiedade }\end{array}$ & 4 semanas & $\begin{array}{l}\text { Quatro semanas de corrida } \\
\text { voluntária resultaram em } \\
\text { alterações específicas das funções } \\
\text { nas sub-regiões do hipocampo no } \\
\text { receptor de serotonina 5-HT1A. }\end{array}$ \\
\hline
\end{tabular}




\begin{tabular}{|c|c|c|c|c|}
\hline $\begin{array}{l}\text { Referência e local do } \\
\text { estudo }\end{array}$ & Animais e grupos & Objetivo & $\begin{array}{l}\text { Tempo de } \\
\text { exposição à roda } \\
\text { de corrida }\end{array}$ & Principais Resultados \\
\hline $\begin{array}{l}\text { Castilla-Ortega et al., } \\
(2013)^{40} \\
\text { Espanha }\end{array}$ & $\begin{array}{l}\text { Camundongos machos } \\
\text { C57BL/6J ×129X1/SvJ }\end{array}$ & $\begin{array}{l}\text { Avaliar se a corrida voluntária } \\
\text { recupera alterações } \\
\text { comportamentais e hipocampais } \\
\text { em camundongos sem o receptor } \\
\text { LPA1, estudando a relação } \\
\text { potencial entre a quantidade de } \\
\text { exercício realizado e seus efeitos. }\end{array}$ & 23 dias & $\begin{array}{l}\text { A distância total percorrida } \\
\text { na roda foi significativamente } \\
\text { relacionada com mudanças na } \\
\text { exploração e nas medidas de } \\
\text { neurogênese. } \\
\text { A análise dos marcadores de } \\
\text { neurogênese confirmam o déficit } \\
\text { na neurogênese hipocampal nos } \\
\text { animais nocaute. }\end{array}$ \\
\hline $\begin{array}{l}\text { Klempin et al., (2013) } \\
\text { Alemanha }\end{array}$ & $\begin{array}{l}\text { Camundongos C57BL/6N } \\
\text { Sedentários } \\
\text { Corredores } \\
\text { Nocaute }\end{array}$ & $\begin{array}{l}\text { Analisar a relação entre a } \\
\text { sinalização da serotonina e a } \\
\text { neurogênese induzida pelo } \\
\text { exercício. }\end{array}$ & 6 dias & $\begin{array}{l}\text { A corrida voluntária aumentou } \\
\text { o número de células BrdU/Sox2 } \\
\text { positivas não-radiais tipo 2a; } \\
\text { A neurogênese induzida pela } \\
\text { corrida é anulada pela falta de } \\
\text { serotonina; }\end{array}$ \\
\hline $\begin{array}{l}\text { Patten et al., }(2013)^{39} \\
\text { Canadá }\end{array}$ & $\begin{array}{l}\text { Ratos Sprague-Dawley machos } \\
\text { Sedentários } \\
\text { Corredores }\end{array}$ & $\begin{array}{l}\text { Avaliar os efeitos de diferentes } \\
\text { períodos de exercício }(3,7,14, \\
28 \text { e } 56 \text { dias) na proliferação e } \\
\text { maturação celular e nas mudanças } \\
\text { funcionais no GD. }\end{array}$ & $\begin{array}{l}3 \text { dias } \\
7 \text { dias } \\
14 \text { dias } \\
28 \text { dias } \\
56 \text { dias }\end{array}$ & $\begin{array}{l}\text { A corrida voluntária em curto } \\
\text { e longo prazo pode aumentar } \\
\text { a proliferação de células no } \\
\text { GD adulto; no entanto, para o } \\
\text { aumento da neurogênese é } \\
\text { necessária a exposição a longos } \\
\text { períodos de exercício. }\end{array}$ \\
\hline $\begin{array}{l}\text { Merritt e Rhodes, (2015)22 } \\
\text { Estados Unidos }\end{array}$ & $\begin{array}{l}\text { Camundongos B6, 129S1, D2, } \\
\text { B6D2F1, e B6129F1 } \\
\text { Sedentários } \\
\text { Corredores }\end{array}$ & $\begin{array}{l}\text { Comparar o efeito da corrida } \\
\text { voluntária sobre a neurogênese } \\
\text { em diferentes linhagens de } \\
\text { animais. }\end{array}$ & 30 dias & $\begin{array}{l}\text { Apesar de ocorrer em diferentes } \\
\text { níveis, todas as linhagens de } \\
\text { camundongos aumentaram } \\
\text { a neurogênese e melhoraram } \\
\text { a aprendizagem no labirinto } \\
\text { aquático por meio da corrida } \\
\text { voluntária. }\end{array}$ \\
\hline
\end{tabular}

dongos C57BL/6. O tempo de exposição à roda de corrida variou entre 3 dias e 6 meses. Em todos os estudos os animais foram dividos em grupos experimentais sedentários e corredores, podendo ainda ser subdivididos em outros grupos de acordo com os outros tratamentos que eventualmente receberam.

O método predominantemente utilizado para avaliação da ocorrência de neurogênese no hipocampo foi a himunohistoquímica $22,23,24,25,26,27,28,29,32,38,39,40,42,43,37$. Além dele, alguns artigos também se utilizaram de técnicas de histologia ${ }^{33,34}$, imunoflorescência ${ }^{42,26,43,29,31}$ e autorradiografia ${ }^{32}$. Os principais marcadores utilizados para rotular as novas células foram o BrdU, na quase totalidade dos estudos desta revisão, e além dele, CldU, ldU, doublecortina, KI-67 e NeuN.

\section{Discussão}

A neurogênese hipocampal induzida pelo exercício físico voluntário em camundongos adultos foi descrita pela primeira vez em 1999 pelo grupo de Van Praag e colaboradores 9 . Esse estudo demonstrou que dois a quatro meses de atividade física voluntária diária resultam em aproximadamente 100\% de aumento no número de novas células granulares geradas no GD do hipocampo. Esses resultados sugerem que a formação de novos neurônios induzida pelo exercício físico voluntário contribui para o aumento do volume da camada granular do GD e também auxiliam nos processos de aprendizagem e memória, analisados através do teste do labirinto aquático de Morris em camundongos C57BL/6.

Um dos primeiros estudos com camundongos com livre acesso à roda de corrida utilizou-se de 5-Bromo-2'-deoxyuridine (BrdU), um marcador da incorporação do DNA da fase $S$ ciclo celular com capacidade para rotular células em processo de divisão, inclusive os novos neurônios do hipocampo ${ }^{44}$, para demonstrar os efeitos 


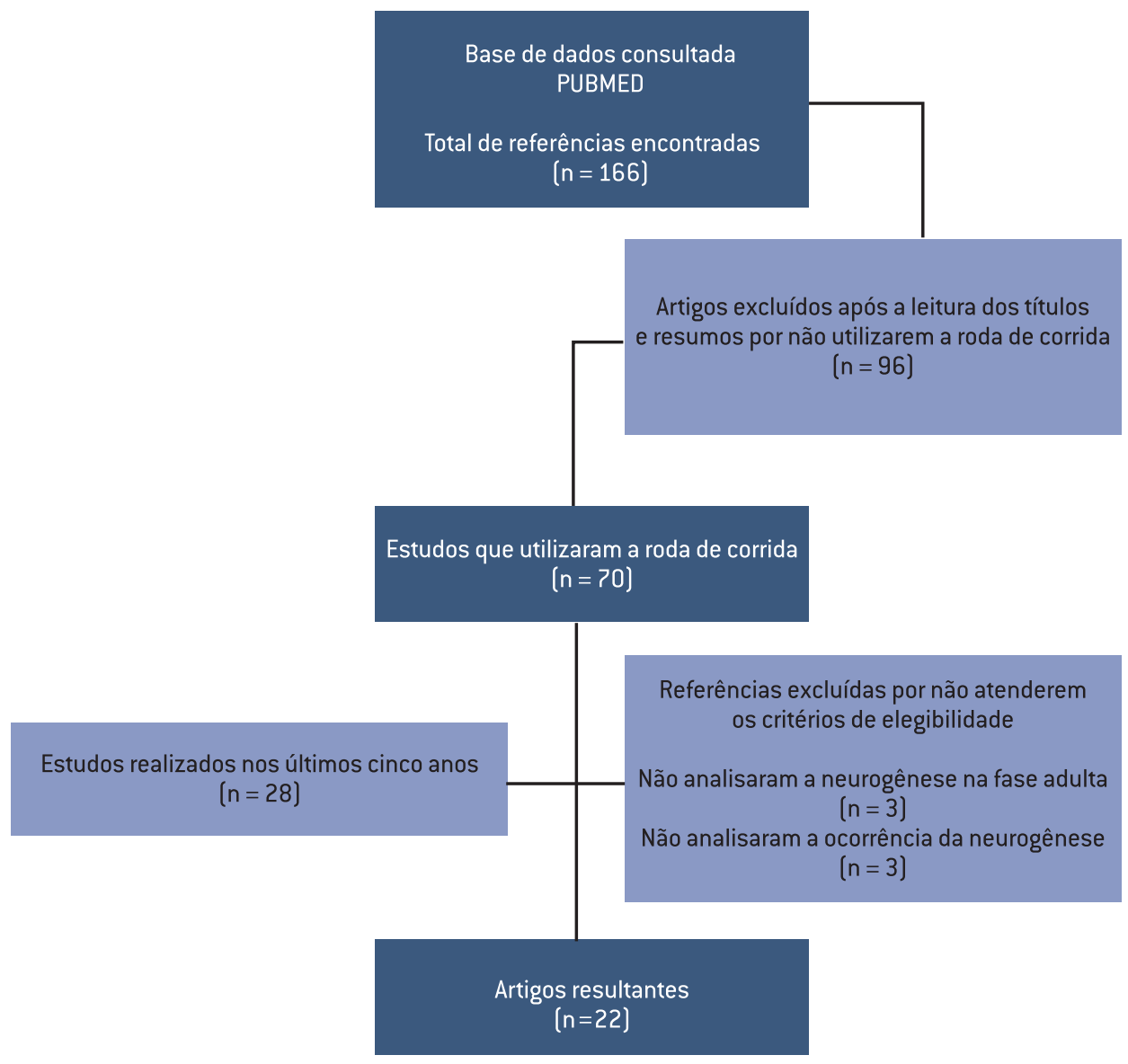

FIGURA 1 - Fluxograma de busca e seleção dos estudos.

da neurogênese. Nesse estudo, um grupo de animais foi treinado no rotarod, outro teve livre acesso à roda de corrida e um terceiro grupo permaneceu experimentalmente naïve. Os resultados demonstraram que os animais treinados no rotarod apresentaram uma quantidade maior de novas células marcadas com BrdU dos que os animais dos outros grupos. Apesar de realizarem uma grande quantidade de atividade física, o grupo que teve acesso à roda de corrida não apresentou mais células do que o grupo naïve, sugerindo que o aprendizado, e não meramente o exercício físico, previnem a morte das células hipocampais ${ }^{44}$. Outro estudo mostrou que a atividade física voluntária em roda de corrida ativa a população quiescente radial no hipocampo ${ }^{45}$, sendo que estas células ativadas eventualmente dão origem a neurônios maduros que são funcionalmente integrados ao circuito hipocampal.

Desde então, evidências têm demonstrado que o exercício físico voluntário, até mesmo em um único dia, melhora a saúde cerebral através do aumento expressivo da neurogênese hipocampal na fase adulta ${ }^{16,46,47}$ e estimula a proliferação celular hipocampal, inclusive em modelos animais de doenças neurológicas, como a doença de Parkinson ${ }^{48}$. A atividade física voluntária melhora também a aprendizagem e a função cognitiva ${ }^{17,50,51}$ além de melhorar a potenciação de longo prazo (LTP), que é um aumento na eficácia sináptica da via perfurante média do GD9 . O fenômeno da LTP foi proposto por Lomo ${ }^{52}$ como a possível base da memória e do aprendizado e é caracterizada como uma melhoria duradoura na transmissão do sinal entre dois neurônios que resulta da estimulação de forma síncrona ${ }^{53}$.

A partir destas evidências a utilização da roda de corrida voluntária como modelo de exercício tornou-se amplamente utilizada nas pesquisas envolvendo ro- 
edores de laboratório e neurogênese hipocampal. Ratos com livre acesso à roda de corrida são extremamente ativos e capazes de correr até $5 \mathrm{~km}$ por noite ${ }^{54}$. Em um período de 7 a 12 dias isso pode resultar na geração de três vezes mais neurônios recém-nascidos no GD do que nos animais sedentários ${ }^{49,54}$. Adicionalmente, a corrida voluntária pode aumentar o fluxo de sangue no $\mathrm{GD}^{55}$ e causar mudanças morfológicas na formação hipocampal que incluem aumento na densidade e na arborização dos espinhos dendríticos ${ }^{56}$.

Estudos ${ }^{25,30,32}$ demonstraram que os animais que realizaram a corrida voluntária apresentaram um aumento duas vezes maior no número de novos neurônios em comparação com os animais sedentários e a distância média percorrida na roda de correr foi significativamente correlacionada com este aumento. A corrida significativamente aumentou o número de células BrdU positivas na camada de células granulares do hipocampo, chegando a $94 \%$ nos corredores e $85 \%$ nos animais sedentários. Além disso, o exercício físico voluntário aumentou a diferenciação de novas células em neurônios e o volume da camada granular do GD em $13 \%{ }^{25}$.

Nishijima e colaboradores ${ }^{38} \mathrm{em}$ um protocolo de 28 dias de corrida voluntária observaram que o número de neurônios significativamente aumentou na região dorsal do GD do hipocampo, sugerindo uma estimulação mais estrita nesta área. No estudo de Liu e colaboradores ${ }^{26}$, 40 dias de corrida voluntária aumentaram significativamente a proliferação celular e a sobrevivência neuronal nas regiões ventral e dorsal do GD, em comparação com animais sedentários. Aguiar e colaboradores $^{57}$, em seu estudo, aplicaram um programa de treinamento constituído por 4 semanas consecutivas em roda de corrida e demonstraram que a atividade física voluntária melhora seletivamente déficits de memória de reconhecimento social em ratos, o que reforça as propriedades do exercício físico na melhora da cognição e sua relação com as funções hipocampais, as quais são particularmente vulneráveis às alterações relacionadas à idade, como a diminuição no seu volume, e o surgimento de déficits funcionais.

Existem diversos mecanismos propostos como explicação para o efeito proliferativo neuronal induzido pelo exercício físico voluntário. Um deles é o aumento do início do ciclo celular devido ao recrutamento de células tronco quiescentes e a redução da saída ou alterações na duração do mesmo ${ }^{58}$. No entanto não está claro se as mudanças em nível de ciclo celular são igualmente causadas pela resposta fisiológica do pool de células precursoras no hipocampo adulto ou estímulos extrínsecos como o exercício físico ${ }^{16,49}$.

Muito recentemente também foi reportado que a neurogênese hipocampal induzida pelo exercício físico é dependente dos neurônios colinérgicos septais ${ }^{13}$. Após a inibição destes neurônios pela injeção de p75-SAP, inibiu-se também o efeito benéfico da atividade física voluntária em roda de corrida sobre a proliferação de células-tronco neurais. Esse efeito foi também encontrado em camundongos velhos ( $>2$ anos). Esses achados sugerem que a acetilcolina liberada durante a corrida na roda pode ativar os receptores muscarínicos sobre as células estaminais neurais.

Também, diversas neurotrofinas como o fator neurotrófico derivado do encéfalo (BDNF) e o IGF-1 (insulin-like growth factor) têm sido sugeridos como potenciais mediadores necessários para a plasticidade hipocampal induzida pelo exercício físico. $\mathrm{O}$ aumento da neurogênese e a conseqüente melhora da função são paralelas ao aumento da regulação do BDNF no cérebro, o qual possivelmente é causado pela captação de IGF-1 mediada pelo exercício físico ${ }^{59}$. O estudo de Ke e colaboradores ${ }^{60}$ demonstrou que a corrida voluntária é mais efetiva na recuperação motora e no aumento dos níveis de BDNF no hipocampo do que o exercício forçado. 
Dada a associação positiva entre neurogênese hipocampal, níveis de neurotrofinas (BDNF e IGF-1) e melhoras cognitivas após o exercício físico, Yau e colaboradores $^{41}$ investigaram se alterações nas neurotrofinas hipocampais são acompanhadas por mudanças correspondentes na proliferação celular. Para isso, utilizaram tratamentos agudos e crônicos com corticosterona, que exerce efeito sobre essas neurotrofinas, em animais sedentários e corredores. No tratamento agudo por 5 dias, a corrida e a corticosterona não exerceram efeitos sobre a modulação da taxa de proliferação celular hipocampal. Já no tratamento crônico, esta taxa foi significativamente aumentada pela corrida em relação aos animais sedentários e o exercício foi capaz de anular os efeitos da corticosterona.

A seguir, os autores investigaram a relação entre a melhora cognitiva e o aumento nos níveis de BDNF e IGF-1 periféricos nos animais expostos à roda de corrida voluntária, porém, não foram observadas alterações significativas em ambos após 28 dias de corrida. Diferentemente, no estudo de Patenn e colaboradores ${ }^{39}$, que também analisaram diferentes protocolos de exercício os autores verificaram que longos períodos de acesso à roda de corrida significativamente aumentaram o número de neurônios imaturos no GD (14 e 28 dias) e a proliferação celular (28 dias).

O prejuízo na aprendizagem espacial, a diminuição dos níveis de BDNF e a supressão da proliferação de células do hipocampo não foram associados com alterações periféricas significativas após o tratamento crônico com corticosterona. Além disso, os efeitos benéficos da corrida na proliferação de células do hipocampo em ratos normais e tratados ocorreram na ausência de alterações significativas nos níveis periféricos de neurotrofinas ${ }^{41}$. Os efeitos de longos períodos de corrida voluntária na neurogênese hipocampal na fase adulta e nos níveis de BDNF também foram avaliados em outro estudo ${ }^{43}$. Os resultados demonstraram que seis meses de corrida voluntária aumentaram a neurogênese hipocampal, quando comparados aos animais sedentários, demonstradas através do número total de novos neurônios e os níveis de BDNF.

Ainda em relação à essa neurotrofina, Kohman e colaboradores ${ }^{31}$ avaliaram as mudanças na expressão dos genes hipocampais e se o exercício aeróbio diferencialmente modula a expressão dos genes em camundongos adultos e envelhecidos. Os resultados mostraram que a corrida voluntária significativamente aumentou a expressão de BDNF tanto em camundongos adultos como nos velhos. Também, indicam que os efeitos benéficos do exercício físico parecem resultar de mudanças em múltiplos padrões que podem ser restaurativos em sujeitos envelhecidos, mas também agem como medida preventiva em sujeitos mais jovens.

As diferenças genéticas entre as espécies devem ser consideradas nas respostas neurogênicas dos roedores ao exercício físico. A maioria dos estudos se utiliza da linhagem C57BL/6 para avaliar a ocorrência da neurogênese induzida pelo exercício, porém, diversas outras espécies foram analisadas nos estudos incluídos nessa revisão, a fim de estabelecer comparações. O aumento quantitativo no número total de novos neurônios em resposta à corrida voluntária na roda difere entre elas, com algumas mostrando relativamente mais novos neurônios para a mesma quantidade de corrida em comparação com as outras ${ }^{24}$.

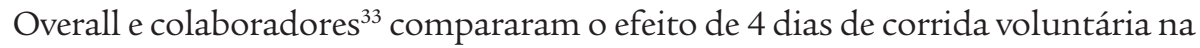
roda em duas espécies diferentes de camundongos, DBA/2 e C57BL/6 e observaram que apesar de ambos os grupos apresentarem um padrão muito similar da distância percorrida na roda, a linhagem DBA/2 exibiu diferenças significativas em relação à linhagem C57BL/6, incluindo um número menor na proliferação de células precursoras hipocampais, ausência dos efeitos da atividade física nas mesmas células após 
4 dias de corrida e uma correlação negativa entre a distância percorrida por esses animais na roda com o número de células BrdU positivas.

Para verificar se camundongos DBA/2 requerem um maior período de exposição à roda para apresentarem efeitos neurogênicos o mesmo experimento foi repetido por 28 dias e então foram encontrados níveis de proliferação semelhantes aos da outra espécie, mostrando que a ausência inicial de resposta destes animais foi transitória e que existe um atraso de aproximadamente uma semana no aumento da proliferação de precursores hipocampais em relação aos camundongos C57BL/6.

De forma semelhante Klaus e colaboradores ${ }^{42}$ analisaram camundongos C57BL/6 e camundongos domésticos selvagens e estabeleceram uma comparação das diferenças no desempenho na corrida, na proliferação e morte celular e número de novos neurônios entre as espécies. A quantidade de corrida na roda foi semelhante entre as duas espécies, porém, os camundongos domésticos apresentaram uma maior variabilidade entre eles, além de uma consistente, porém não significativa tendência no aumento das células proliferativas e dos neurônios maduros, ao contrário do observado em C57BL/6.

Clark e colaboradores ${ }^{24}$ examinaram as diferenças na neurogênese em 12 espécies diferentes de camundongos (129S1/SvImJ, AKR/J, B6129SF1/J, B6D2F1/J, BALB/cByJ, BTBR T+ tf/J, C57BL/10J, C57BL/6, CAST/EiJ, DBA/2J, NOD/ShiLtJ, e $\mathrm{SM} / \mathrm{J})$. A corrida voluntária significativamente aumentou a neurogênese hipocampal na fase adulta em todas as espécies, contudo, a magnitude do efeito foi dependente do genótipo. Interessantemente, C57BL/6, a espécie mais frequentemente usada neste tipo de estudos foi a que apresentou menores respostas neurogênicas através de um pequeno aumento de 1,6 vezes, enquanto que nas outras espécies a neurogênese mais do que dobrou após a corrida, chegando a 4 a 5 vezes nas espécies AKR/J, B6129SF1/J, BALB/cByJ, CAST/EiJ e SM/J. Este estudo ilustra a robustez dos efeitos da corrida na roda no aumento da neurogênese hipocampal e a importância do background genético para a determinação na magnitude da resposta neuroplástica. A resposta pode estar nos genes que regulam a sinalização de fatores neurotróficos como o BDNF e o IGF-1, genes que são expressos durante o desenvolvimento neuronal (ex: nestina, doublecortina) e genes que regulam o metabolismo celular.

Muito recentemente Merritt e Rhodes ${ }^{22}$ compararam os níveis da neurogênese hipocampal na fase adulta em cinco diferentes espécies de camundongos e observaram que os efeitos neurogênicos do exercício foram similares em todas as espécies aumentando significativamente o número de novos neurônios na camada granular das mesmas, porém em maior quantidade em C57BL/6, seguido das espécies B6129F1, 129S1, B6D2F1 e D2, sendo a primeira significativamente maior do que as outras espécies, exceto B6129F1. A explicação para essas diferenças também parece estar na carga genética dos animais analisados.

Por fim, alguns estudos buscaram elucidar a relação entre a neurogênese hipocampal, o desenvolvimento de um comportamento ansioso e a irradiação cranial. A irradiação é um tratamento chave utilizado em pacientes com tumores cerebrais primários ou metásticos, podendo também ser usada como tratamento profilático para tumores sólidos avançados. Contudo, causa déficits progressivos e persistentes no aprendizado e na memória, prejudicando a qualidade de vida ${ }^{66,67}$.

Alguns estudos apontam para uma diminuição da neurogênese devido ao aumento da ansiedade ${ }^{61,62}$, enquanto outros evidenciam o contrário ${ }^{63,64}$. Em vista disso, Garrett e colaboradores ${ }^{37}$ investigaram se a neurogênese induzida pelo exercício ocasiona um aumento da mesma utilizando-se de dois protocolos de exercício, 
14 ou 28 dias de corrida voluntária, porém nenhum deles apresentou efeitos ansiolíticos ou ansiogênicos. Ambos os protocolos influenciaram os vários estágios da neurogênese com a proliferação aumentando após 14 dias, sobrevivência sendo elevada após 14 e 28 dias e a taxa de diferenciação e maturação de novos neurônios aumentando após 28 dias em comparação aos animais sedentários.

Enquanto a corrida voluntária aumenta significativamente a neurogênese hipocampal em roedores ${ }^{9}$ a irradiação cranial resulta em reduções fortes e em longo prazo da neurogênese na fase adulta, dependendo da dose administrada ${ }^{65,68,69}$. Dadas essas conseqüências devastadoras, intervenções para prevenir ou atenuar os déficits nas funções neurais e cognitivas causados pela irradiação tornam-se necessários.

Em vista disso, Fuss e colaboradores ${ }^{34,35}$ hipotetizaram que mudanças neuroquímicas também ocorrem após a irradiação e observaram em seu estudo que esta exerce efeitos negativos na neurogênese na SGZ. Animais irradiados foram expostos à roda de corrida por 4 semanas e essa ação não teve influência positiva significativa no número de células expressas pelo marcador Ki67 nesta mesma região. A seguir, os autores avaliaram se essa irradiação dificulta o desenvolvimento de um comportamento ansioso ocasionado pela corrida voluntária e constataram que esses efeitos são completamente abolidos pela irradiação no teste comportamental de campo aberto. Contrastando com os efeitos na neurogênese e na ansiedade a irradiação não afetou os níveis de BDNF no hipocampo, tanto em corredores como em sedentários.

Estes achados foram também corroborados por outro estudo que se utilizou deste mecanismo molecular para bloquear a neurogênese $e^{28}$. Quando a mesma é eliminada pela irradiação ou por abordagens moleculares camundongos corredores passam a não mais exibir um aumento no comportamento ansioso, indicando que a neurogênese hipocampal pode ser um importante fator de desenvolvimento deste fenótipo ${ }^{28,34}$. No estudo de Castilla-Ortega e colaboradores ${ }^{40}, 23$ dias de corrida voluntária diminuíram o comportamento ansioso e aumentaram o comportamento exploratório dos animais, além de aumentar a neurogênese no GD do hipocampo.

Poucos estudos examinaram os efeitos do exercício nas funções cognitivas e neurogênicas após a irradiação cranial na idade adulta, entretanto, os resultados são consistentes com a recuperação $0^{70,71}$ ou por não exercerem efeitos sobre a mesma, sendo, portanto, um tema que permanece ainda em discussão. Em vista disso, Wong-Goodrich e colaboradores ${ }^{29}$ investigaram os efeitos de 6 semanas de corrida voluntária no aprendizado e na memória espacial e na neurogênese na fase adulta após a irradiação. Os resultados deste estudo demonstraram que o declínio na memória causado pela irradiação foi prevenido pela corrida voluntária diária. Essa recuperação foi acompanhada por uma restauração parcial da neurogênese no GD e esses efeitos pareceram ser independentes da neuroinflamação hipocampal persistente. Estes resultados sugerem que a atividade física voluntária pode recuperar as funções hipocampais e a neurogênese após o tratamento com irradiação.

Progressos significativos têm sido feitos desde a última década em relação à elucidação da função e da regulação da neurogênese em roedores. A literatura é clara ao estabelecer que esse fenômeno é contínuo ao longo da vida nos mamíferos e é influenciado por fatores externos como o exercício físico. A roda de corrida voluntária é uma ferramenta amplamente utilizada na modelagem desse processo, devido à sua comprovada eficácia na promoção da neurogênese hipocampal na fase adulta.

A exata contribuição desse mecanismo na função cerebral permanece indefinida, sendo necessária uma clara elucidação do mesmo, contudo, o uso de modelos experimentais que simulem as condições neuropatológicas tem sido útil para o 
entendimento da sua fisiopatologia e da aplicabilidade do exercício físico como uma terapia adjuvante ao seu tratamento ${ }^{72}$. É indubitável o benefício que a prática regular de exercício físico, seja ele recreacional ou competitivo, pode trazer aos indivíduos com neuropatologias, devendo ser levadas em consideração as possibilidades e limitações de cada uma delas.

Como pontos positivos deste manuscrito destacam-se o ineditismo da proposta e a síntese sistemática dos principais resultados sobre a ocorrência da neurogênese hipocampal na fase adulta. Dentre as limitações apontam-se o curto período de tempo de inclusão dos artigos publicados (5 anos), a não inclusão de um segundo revisor na extração dos dados e a restrição às publicações em português e inglês.

\section{Agradecimentos}

À CAPES pelo apoio financeiro.

\section{Referências}

1. Altman J, Altman E. Increased utilization of an amino acid and cellular proliferation demonstrated autoradiographically in the optic pathways of pigeons. Exp Neurol. 1962 Aug;6:142-51. PubMed PMID: 13860744. Epub 1962/08/01. eng.

2. Gould E, Cameron HA. Regulation of neuronal birth, migration and death in the rat dentate gyrus. Dev Neurosci. 1996;18(1-2):22-35. PubMed PMID: 8840084.

3. Gage FH. Mammalian neural stem cells. Science. 2000 Feb 25;287(5457):1433-8. PubMed PMID: 10688783.

4. Temple S. The development of neural stem cells. Nature. 2001 Nov 1;414(6859):112-7. PubMed PMID: 11689956.

5. Ming GL, Song H. Adult neurogenesis in the mammalian central nervous system. Annu Rev neurosci. 2005;28:223-50. PubMed PMID: 16022595.

6. Zhao C, Deng W, Gage FH. Mechanisms and functional implications of adult neurogenesis. Cell. 2008 Feb 22;132(4):645-60. PubMed PMID: 18295581.

7. Sawamoto K, Wichterle H, Gonzalez-Perez O, Cholfin JA, Yamada M, Spassky N, et al. New neurons follow the flow of cerebrospinal fluid in the adult brain. Science. 2006 Feb 3;311(5761):629-32. PubMed PMID: 16410488.

8. Suh H, Deng W, Gage FH. Signaling in adult neurogenesis. Annu Rev Cell Dev Biol. 2009;25:253-75. PubMed PMID: 19575663. Epub 2009/07/07. eng.

9. van Praag H, Christie BR, Sejnowski TJ, Gage FH. Running enhances neurogenesis, learning, and long-term potentiation in mice. Proc Natl Acad Sci USA. 1999 Nov 9;96(23):13427-31. PubMed PMID: 10557337. PMCID: 23964. Epub 1999/11/11. eng.

10. Gould E, Tanapat P, Hastings NB, Shors TJ. Neurogenesis in adulthood: a possible role in learning. Trends Cogn Sci. 1999 May;3(5):186-92. PubMed PMID: 10322475.

11. Fukuda S, Kato F, Tozuka Y, Yamaguchi M, Miyamoto Y, Hisatsune T. Two distinct subpopulations of nestin-positive cells in adult mouse dentate gyrus. J Neurosci. 2003 Oct 15;23(28):9357-66. PubMed PMID: 14561863.

12. Kempermann G, Jessberger S, Steiner B, Kronenberg G. Milestones of neuronal development in the adult hippocampus. Trends Neurosci. 2004 Aug;27(8):447-52. PubMed PMID: 15271491.

13. Itou Y, Nochi R, Kuribayashi H, Saito Y, Hisatsune T. Cholinergic activation of hippocampal neural stem cells in aged dentate gyrus. Hippocampus. 2011 Apr;21(4):44659. PubMed PMID: 20054812.

14. Okano H. Stem cell biology of the central nervous system. J Neurosci Res. 2002 Sep 15;69(6):698-707. PubMed PMID: 12205662.

15. Middleton LE, Manini TM, Simonsick EM, Harris TB, Barnes DE, Tylavsky F, et al. Activity energy expenditure and incident cognitive impairment in older adults. Arch Intern Med. 2011 Jul 25;171(14):1251-7. PubMed PMID: 21771893. Epub 2011/07/21. eng.

16. van Praag H, Kempermann G, Gage FH. Running increases cell proliferation and neurogenesis in the adult mouse dentate gyrus. Nat Neurosci. 1999 Mar;2(3):266-70. PubMed PMID: 10195220. Epub 1999/04/09. eng. 
17. Johansson BB, Ohlsson A. Environment, social interaction and physical activity as determinants of functional outcome after cerebral activity in the rat. Exp Neurol. 1997;139:322-7.

18. Van der Borght K, Havekes R, Bos T, Eggen BJ, Van der Zee EA. Exercise improves memory acquisition and retrieval in the Y-maze task: relationship with hippocampal neurogenesis. Behav Neurosci. 2007 Apr;121(2):324-34. PubMed PMID: 17469921.

19. van Praag H, Shubert T, Zhao C, Gage FH. Exercise enhances learning and hippocampal neurogenesis in aged mice. J Neurosci. 2005 Sep 21;25(38):8680-5. PubMed PMID: 16177036. PMCID: 1360197.

20. Nilsson M, Perfilieva E, Johansson U, Orwar O, Eriksson PS. Enriched environment increases neurogenesis in the adult rat dentate gyrus and improves spatial memory. J Neurobiol. 1999 Jun 15;39(4):569-78. PubMed PMID: 10380078.

21. Kempermann G, Gast D, Gage FH. Neuroplasticity in old age: sustained fivefold induction of hippocampal neurogenesis by long-term environmental enrichment. Ann Neurol. 2002 Aug;52(2):135-43. PubMed PMID: 12210782.

22. Merritt JR, Rhodes JS. Mouse genetic differences in voluntary wheel running, adult hippocampal neurogenesis and learning on the multi-strain-adapted plus water maze. Behav Brain res. 2015 Mar 1;280:62-71. PubMed PMID: 25435316. PMCID: 4280099.

23. Maynard ME, Leasure JL. Exercise enhances hippocampal recovery following binge ethanol exposure. PloS one. 2013;8(9):e76644. PubMed PMID: 24098797. PMCID: 3786922.

24. Clark PJ, Kohman RA, Miller DS, Bhattacharya TK, Brzezinska WJ, Rhodes JS. Genetic influences on exercise-induced adult hippocampal neurogenesis across 12 divergent mouse strains. Genes Brain Behav. 2011 Apr;10(3):345-53. PubMed PMID: 21223504. PMCID: 3139814.

25. Clark PJ, Bhattacharya TK, Miller DS, Rhodes JS. Induction of c-Fos, Zif268, and Arc from acute bouts of voluntary wheel running in new and pre-existing adult mouse hippocampal granule neurons. Neuroscience. 2011 Jun 16;184:16-27. PubMed PMID: 21497182. PMCID: 3100453.

26. Liu J, Somera-Molina KC, Hudson RL, Dubocovich ML. Melatonin potentiates running wheel-induced neurogenesis in the dentate gyrus of adult $\mathrm{C} 3 \mathrm{H} / \mathrm{HeN}$ mice hippocampus. J Pineal Res. 2013 Mar;54(2):222-31. PubMed PMID: 23190173. PMCID: 3568494.

27. Clark PJ, Bhattacharya TK, Miller DS, Kohman RA, DeYoung EK, Rhodes JS. New neurons generated from running are broadly recruited into neuronal activation associated with three different hippocampus-involved tasks. Hippocampus. 2012 Sep;22(9):1860-7. PubMed PMID: 22467337. PMCID: 3390440.

28. Onksen JL, Briand LA, Galante RJ, Pack AI, Blendy JA. Running-induced anxiety is dependent on increases in hippocampal neurogenesis. Genes Brain Behav. 2012 Jul;11(5):529-38. PubMed PMID: 22471438. PMCID: 3389278.

29. Wong-Goodrich SJ, Pfau ML, Flores CT, Fraser JA, Williams CL, Jones LW. Voluntary running prevents progressive memory decline and increases adult hippocampal neurogenesis and growth factor expression after whole-brain irradiation. Cancer Res. 2010 Nov 15;70(22):9329-38. PubMed PMID: 20884629. PMCID: 2982943.

30. Kohman RA, Clark PJ, Deyoung EK, Bhattacharya TK, Venghaus CE, Rhodes JS. Voluntary wheel running enhances contextual but not trace fear conditioning. Behav Brain Res. 2012 Jan 1;226(1):1-7. PubMed PMID: 21896289. PMCID: 3197746.

31. Kohman RA, Rodriguez-Zas SL, Southey BR, Kelley KW, Dantzer R, Rhodes JS. Voluntary wheel running reverses age-induced changes in hippocampal gene expression. PloS one. 2011;6(8):e22654. PubMed PMID: 21857943. PMCID: 3152565.

32. Mustroph ML, Stobaugh DJ, Miller DS, DeYoung EK, Rhodes JS. Wheel running can accelerate or delay extinction of conditioned place preference for cocaine in male C57BL/6J mice, depending on timing of wheel access. Eur J Neurosci. 2011 Oct;34(7):1161-9. PubMed PMID: 21864322. PMCID: 3186851.

33. Overall RW, Walker TL, Leiter O, Lenke S, Ruhwald S, Kempermann G. Delayed and transient increase of adult hippocampal neurogenesis by physical exercise in DBA/2 mice. PloS one. 2013;8(12):e83797. PubMed PMID: 24376750. PMCID: 3869944.

34. Fuss J, Ben Abdallah NM, Hensley FW, Weber KJ, Hellweg R, Gass P. Deletion of runninginduced hippocampal neurogenesis by irradiation prevents development of an anxious phenotype in mice. PloS one. 2010;5(9). PubMed PMID: 20862278. PMCID: 2940841.

35. Fuss J, Vogt MA, Weber KJ, Burke TF, Gass P, Hensler JG. Hippocampal serotonin-1A receptor function in a mouse model of anxiety induced by long-term voluntary wheel running. Synapse. 2013 Oct;67(10):648-55. PubMed PMID: 23505009. PMCID: 3816532. 
36. Klempin F, Beis D, Mosienko V, Kempermann G, Bader M, Alenina N. Serotonin is required for exercise-induced adult hippocampal neurogenesis. J Neurosci. 2013 May 8;33(19):8270-5. PubMed PMID: 23658167.

37. Garrett L, Lie DC, Hrabe de Angelis M, Wurst W, Holter SM. Voluntary wheel running in mice increases the rate of neurogenesis without affecting anxiety-related behaviour in single tests. BMC Neurosci. 2012;13:61. PubMed PMID: 22682077. PMCID: 3504529.

38. Nishijima T, Kawakami M, Kita I. Long-term exercise is a potent trigger for DeltaFosB induction in the hippocampus along the dorso-ventral axis. PloS one. 2013;8(11):e81245. PubMed PMID: 24282574. PMCID: 3840114.

39. Patten AR, Sickmann H, Hryciw BN, Kucharsky T, Parton R, Kernick A, et al. Long-term exercise is needed to enhance synaptic plasticity in the hippocampus. Learn Mem. 2013 Nov; 20(11):642-7. PubMed PMID: 24131795.

40. Castilla-Ortega E, Rosell-Valle C, Blanco E, Pedraza C, Chun J, Rodriguez de Fonseca F, et al. Reduced wheel running and blunted effects of voluntary exercise in LPA1-null mice: the importance of assessing the amount of running in transgenic mice studies. Neurosci Res. 2013 Nov;77(3):170-9. PubMed PMID: 24055600. PMCID: 4006933.

41. Yau SY, Lau BW, Zhang ED, Lee JC, Li A, Lee TM, et al. Effects of voluntary running on plasma levels of neurotrophins, hippocampal cell proliferation and learning and memory in stressed rats. Neuroscience. 2012 Oct 11;222:289-301. PubMed PMID: 22813995.

42. Klaus F, Hauser T, Lindholm AK, Cameron HA, Slomianka L, Lipp HP, et al. Different regulation of adult hippocampal neurogenesis in Western house mice (Mus musculus domesticus) and C57BL/6 mice. Behav Brain Res. 2012 Feb 14;227(2):340-7. PubMed PMID: 21803074. PMCID: 3212619.

43. Marlatt MW, Potter MC, Lucassen PJ, van Praag H. Running throughout middle-age improves memory function, hippocampal neurogenesis, and BDNF levels in female C57BL/6J mice. Dev Neurobiol. 2012 Jun;72(6):943-52. PubMed PMID: 22252978. PMCID: 3485396.

44. Curlik DM, 2nd, Maeng LY, Agarwal PR, Shors TJ. Physical skill training increases the number of surviving new cells in the adult hippocampus. PloS one. 2013;8(2):e55850. PubMed PMID: 23437067. PMCID: 3577803.

45. Lugert S, Basak O, Knuckles P, Haussler U, Fabel K, Gotz M, et al. Quiescent and active hippocampal neural stem cells with distinct morphologies respond selectively to physiological and pathological stimuli and aging. Cell stem cell. 2010 May 7;6(5):445-56. PubMed PMID: 20452319.

46. Madsen TM, Treschow A, Bengzon J, Bolwig TG, Lindvall O, Tingstrom A. Increased neurogenesis in a model of electroconvulsive therapy. Biol Psychiatry. 2000 Jun 15;47(12):1043-9. PubMed PMID: 10862803.

47. van Praag H, Kempermann G, Gage FH. Neural consequences of environmental enrichment. Nat Rev Neurosci. 2000 Dec;1(3):191-8. PubMed PMID: 11257907.

48. Tapia-Rojas C, Aranguiz F, Varela-Nallar L, Inestrosa NC. Voluntary running attenuates memory loss, decreases neuropathological changes and induces neurogenesis in a mouse model of Alzheimer's disease. Brain Pathol. 2015 Mar 11. PubMed PMID: 25763997.

49. Kronenberg G, Reuter K, Steiner B, Brandt MD, Jessberger S, Yamaguchi M, et al. Subpopulations of proliferating cells of the adult hippocampus respond differently to physiologic neurogenic stimuli. J Comp Neurol. 2003 Dec 22;467(4):455-63. PubMed PMID: 14624480.

50. Ehninger D, Kempermann G. Regional effects of wheel running and environmental enrichment on cell genesis and microglia proliferation in the adult murine neocortex. Cereb cortex. 2003 Aug;13(8):845-51. PubMed PMID: 12853371.

51. Fordyce DE, Wehner JM. Physical activity enhances spatial learning performance with an associated alteration in hippocampal protein kinase $\mathrm{C}$ activity in C57BL/6 and DBA/2 mice. Brain Res. 1993 Aug 13;619(1-2):111-9. PubMed PMID: 8374769.

52. Lomo T. The discovery of long-term potentiation. Philosophical transactions of the Royal Society of London Series B, Biol Sci. 2003 Apr 29;358(1432):617-20. PubMed PMID: 12740104. PMCID: 1693150. Epub 2003/05/13. eng.

53. Cooke SF, Bliss TV. Plasticity in the human central nervous system. Brain. $2006 \mathrm{Jul} ; 129(\mathrm{Pt}$ 7):1659-73. PubMed PMID: 16672292. Epub 2006/05/05. eng.

54. Farmer J, Zhao X, van Praag H, Wodtke K, Gage FH, Christie BR. Effects of voluntary exercise on synaptic plasticity and gene expression in the dentate gyrus of adult male Sprague-Dawley rats in vivo. Neuroscience. 2004;124(1):71-9. PubMed PMID: 14960340.

55. Pereira AC, Huddleston DE, Brickman AM, Sosunov AA, Hen R, McKhann GM, et al. An in vivo correlate of exercise-induced neurogenesis in the adult dentate gyrus. Proc Natl Acad Sci USA. 2007 Mar 27;104(13):5638-43. PubMed PMID: 17374720. PMCID: 1838482. 
56. Redila VA, Christie BR. Exercise-induced changes in dendritic structure and complexity in the adult hippocampal dentate gyrus. Neuroscience. 2006;137(4):1299-307. PubMed PMID: 16338077.

57. Aguiar AS, Jr., Araujo AL, da-Cunha TR, Speck AE, Ignacio ZM, De-Mello N, et al. Physical exercise improves motor and short-term social memory deficits in reserpinized rats. Brain Res Bull. 2009 Aug 14;79(6):452-7. PubMed PMID: 19463920.

58. Lange C, Huttner WB, Calegari F. Cdk4/cyclinD1 overexpression in neural stem cells shortens G1, delays neurogenesis, and promotes the generation and expansion of basal progenitors. Cell stem cell. 2009 Sep 4;5(3):320-31. PubMed PMID: 19733543.

59. Carro E, Nunez A, Busiguina S, Torres-Aleman I. Circulating insulin-like growth factor I mediates effects of exercise on the brain. J Neurosci. 2000 Apr 15;20(8):2926-33. PubMed PMID: 10751445.

60. Ke Z, Yip SP, Li L, Zheng XX, Tong KY. The effects of voluntary, involuntary, and forced exercises on brain-derived neurotrophic factor and motor function recovery: a rat brain ischemia model. PloS one. 2011;6(2):e16643. PubMed PMID: 21347437. PMCID: 3035657.

61. Revest JM, Dupret D, Koehl M, Funk-Reiter C, Grosjean N, Piazza PV, et al. Adult hippocampal neurogenesis is involved in anxiety-related behaviors. Mol Psy. 2009 Oct;14(10):959-67. PubMed PMID: 19255582.

62. Schloesser RJ, Manji HK, Martinowich K. Suppression of adult neurogenesis leads to an increased hypothalamo-pituitary-adrenal axis response. Neuroreport. 2009 Apr 22;20(6):553-7. PubMed PMID: 19322118. PMCID: 2693911.

63. Saxe MD, Battaglia F, Wang JW, Malleret G, David DJ, Monckton JE, et al. Ablation of hippocampal neurogenesis impairs contextual fear conditioning and synaptic plasticity in the dentate gyrus. Proc Natl Acad Sci USA. 2006 Nov 14;103(46):17501-6. PubMed PMID: 17088541. PMCID: 1859958.

64. Onksen JL, Brown EJ, Blendy JA. Selective deletion of a cell cycle checkpoint kinase (ATR) reduces neurogenesis and alters responses in rodent models of behavioral affect. Neuropsychopharmacology. 2011 Apr;36(5):960-9. PubMed PMID: 21248719. PMCID: 3077265.

65. Mizumatsu S, Monje ML, Morhardt DR, Rola R, Palmer TD, Fike JR. Extreme sensitivity of adult neurogenesis to low doses of X-irradiation. Cancer Res. 2003 Jul 15;63(14):40217. PubMed PMID: 12874001.

66. Meyers CA, Smith JA, Bezjak A, Mehta MP, Liebmann J, Illidge T, et al. Neurocognitive function and progression in patients with brain metastases treated with whole-brain radiation and motexafin gadolinium: results of a randomized phase III trial. J Clin oncol Oncology. 2004 Jan 1;22(1):157-65. PubMed PMID: 14701778.

67. Marko NF, Weil RJ. Radiotherapy: Neurocognitive considerations in the treatment of brain metastases. Nat Rev Clin Oncol. 2010 Apr;7(4):185-6. PubMed PMID: 20354539.

68. Deng W, Saxe MD, Gallina IS, Gage FH. Adult-born hippocampal dentate granule cells undergoing maturation modulate learning and memory in the brain. J Neurosci. 2009 Oct 28;29(43):13532-42. PubMed PMID: 19864566. PMCID: 2787190.

69. Kitamura T, Saitoh Y, Takashima N, Murayama A, Niibori Y, Ageta H, et al. Adult neurogenesis modulates the hippocampus-dependent period of associative fear memory. Cell. 2009 Nov 13;139(4):814-27. PubMed PMID: 19914173.

70. Clark PJ, Brzezinska WJ, Thomas MW, Ryzhenko NA, Toshkov SA, Rhodes JS. Intact neurogenesis is required for benefits of exercise on spatial memory but not motor performance or contextual fear conditioning in C57BL/6J mice. Neuroscience. 2008 Sep 9;155(4):1048-58. PubMed PMID: 18664375.

71. Naylor AS, Bull C, Nilsson MK, Zhu C, Bjork-Eriksson T, Eriksson PS, et al. Voluntary running rescues adult hippocampal neurogenesis after irradiation of the young mouse brain. Proc Natl Acad Sci USA. 2008 Sep 23;105(38):14632-7. PubMed PMID: 18765809. PMCID: 2567198.

72. Arida RM, Cavalheiro EA, Silva AC, Scorza FA. Physical activity and epilepsy: proven and predicted benefits. Sports Medicine, Auckland, v.38, n.6, p.1-9, 2008.

ENDEREÇO PARA CORRESPONDÊNCIA ANELISE BAVARESCO anebyane@yahoo.com.br
Rua João Pio Duarte Silva, 682,

Ap 102 - Bloco A4, Córrego Grande,

Florianópolis - SC. CEP: 8803700

Tel.: $48-84906706$ 